\title{
Dissertações do Programa de Pós-Graduação em Antropologia Social da UFPR - 2005
}

Título: Anfitriões Guerreiros: Um estudo sobre rivalidades e generosidade nos Kagwahiva Parintintin

Autora: Ângela Kurovski

Orientador: Marcos Pazzanese Duarte Lanna

Co-orientadora: Andréa Mendes de Oliveira Castro

Data da defesa: 21 de março de 2005

Resumo: Este trabalho analisa várias dimensões da vida social Parintintin, especialmente os ritos, as trocas e as rivalidades que constituem sua cosmologia e história. Pretende ainda compreender como este povo Tupi Kagwahiva do Amazonas se apropria do mundo contemporâneo e coexiste com a sociedade envolvente. $A$ exemplo de Mbahira - o herói trickster que reconstruiu o mundo cultural Kagwahiva pós-dilúvio e que usou de artimanhas para roubar o fogo dos urubus e se apossar das flechas de outros povos, entre outras façanhas - os Parintintin buscam se apropriar das tecnologias e conhecimentos da sociedade nacional de várias formas: seja pela projeção de alianças para o exterior, pela lógica da predação simbólica ou forçando a generosidade generalizada dos seus Outros. Na atualidade, as práticas e discursos dos Parintintin, mais do que apontar para um desuso dos princípios estruturais próprios e, portanto, para uma incorporação dos Parintintin a valores da sociedade nacional, frisam exatamente o contrário: uma aplicação e reelaboração de princípios sociais e culturais próprios, como forma de escapar da não humanidade e de revitalizar sua própria sociedade.

Palavras-chave: generosidade - predação - metades exogâmicas - cosmologia - história - ritos - organização social 
Título: Entre a Aldeia e a Cidade: O "trânsito" dos Guarani e Kaiowá no Mato Grosso do Sul

Autor: José Maria Trajano Vieira

Orientador: Ricardo Cid Fernandes

Data da defesa: 07 de junho de 2005

Resumo: Os Guarani e Kaiowá no Mato Grosso do Sul, como outros Guarani, estão em permanente trânsito entre suas aldeias e as cidades. Há, com efeito, uma articulação entre as "aldeias urbanas" e as "aldeias tradicionais", formando um sistema integrado e ordenado de redes de relações sociais. Os Guarani e Kaiowá no Estado transcendem a sua aldeia de origem e se ligam às suas redes de parentela, espalhadas por diferentes aldeias e cidades, ligadas mais às pessoas do que a lugares. A dissertação apresenta e discute algumas características migratórias das populações indígenas no MS. Subjacente ao percurso da pesquisa, encontra-se a tese de que a migração guarani e kaiowá é melhor entendida como inerente ao seu sistema sociocultural "tradicional", compreendendo as mudanças e transformações como processos autênticos dentro da tradição e portadores de uma lógica própria.

Palavras-chave: Guarani - Kaiowá - migração

Título: Nomes, Rezas e Anzóis: Tradição e herança caiçara

Autora: Eliana do Pilar Rocha

Orientador: Ricardo Cid Fernandes

Data da defesa: 27 de setembro de 2005

Resumo: Esta dissertação apresenta uma etnografia dos peçanos, como são chamados os moradores da Vila das Peças, comunidade insular localizada na llha das Peças, litoral Norte do Estado do Paraná. As relações culturalmente específicas que esta população mantém com o lugar são analisadas a partir do estudo das classificações e dos usos sociais relacionados à natureza. Na Vila das Peças, os processos de construção de uma identidade própria estão baseados em relações de parentesco que vinculam estes moradores a outras comunidades costeiras e insulares. Os domínios do parentesco, da religiosidade, assim como o modo de apropriação do espaço peçano são analisados como expressões de uma organização social tradicional que, nos últimos anos, vem convivendo intensamente com novos atores sociais representados pelos turistas e ambientalistas.

Palavras-chave: Ilha das Peças (PR) - caiçaras - espaço - parentesco - religiosidade - turistas - ambientalistas 
Título: O Turismo e os Kaingang da Terra Indígena de Iraí (RS)

Autora: Flavia Lac

Orientador: Ricardo Cid Fernandes

Data da defesa: 18 de outubro de 2005

Resumo: Este trabalho aborda a apropriação do turismo pelos índios Kaingang da Terra Indígena Iraí, sua tradição de hospitalidade e sua relação com os rituais e agentes do turismo. Os índios Kaingang, habitantes do Sul do Brasil, sofrem hoje com dois grandes problemas: o confinamento em espaços cada vez mais reduzidos e a "invisibilidade" de sua cultura frente à sociedade nacional. No entanto, a criatividade destes índios revela, dentro destas condições, estratégias de reforço de sua alteridade, como o turismo. A Terra Indígena Iraí é a menor área demarcada no Estado do Rio Grande do Sul. Para fazer frente à insuficiência de recursos, a comunidade especializou-se na produção e comércio de artesanato que, apesar de servir também para sua subsistência, é considerado pelos Kaingang da Terra Indígena de Iraí como a verdadeira atividade indígena. A venda de artesanato expõe os Kaingang ao turismo, seja nas águas termais de Iraí ou nas viagens que fazem para efetuar o comércio de seus produtos. $O$ turismo torna-se para os índios desta Terra Indígena uma arena que oportuniza a reivindicação de sua "visibilidade". A afirmação de sua identidade, através das danças resgatadas e utilizadas durante a demarcação da Terra Indígena, tornou-se emblema em sua luta por seus direitos. Hoje, na Terra Indígena Iraí, a estratégia indígena se volta para o turismo. Lá eles recebem turistas de acordo com seus costumes de hospitalidade, esperando receber em troca, o respeito dos turistas.

Palavras-chave: Kaingang - Terra Indígena Iraí (RS) - artesanato - turismo - identidade 
Para receber CAMPOS - Revista de Antropologia Social pelo correio, envie seu pedido, anexando cheque nominal à FUNPAR ou comprovante de depósito no Banco Itaú, agência 4012, conta corrente $n^{\circ}$ 13189-4, para o seguinte endereço:

CAMPOS - Revista de Antropologia Social

Universidade Federal do Paraná

Programa de Pós-Graduação em Antropologia Social

Rua General Carneiro, $460-6^{\circ}$ andar

80.060-150 Curitiba - Paraná - Brasil

e-mail:campos@ufpr.br

O comprovante de depósito bancário poderá ser enviado também pelo fax (41) 3360-5316.

Volume $6-2005$

$n^{\circ} 1-2-R \$ 15,00$

Volume 5 - 2004

$n^{\circ} 2-R \$ 12,00$

$n^{\circ} 1-R \$ 12,00$

Volume 4 - 2003 - R\$10,00

Volume 3 - 2003 - R\$ 10,00

Volume 2 - 2002 - $R \$ 8,00$

Volume 1 - 2001 - R\$ 8,00

Coleção completa: $\mathrm{R} \$ 60,00$ 


\section{CAMPOS - Revista de Antropologia Social Sumários das edições anteriores}

\section{Volume 01 - 2001}

Clarice Cohn - Indios Missionários: cultos protestantes entre os Xicrin do Bacajá

Odair Giraldin - Um Mundo Unificado: uma interpretação da teoria Apinaje sobre doença, cura e morte

William J. Bajor - Discussing "Human Rights" with the Displaced: the use of 'religion' and other discursive devices by displaced sudanese in "human rights" discourse

Julie Cavignac - Destinos Migrantes: representações do espaço, histórias de vida e narrativas

Leandro Etchichury - El Señor de la Producción: relaciones entre agrónomos y desempleados rurales en un proyecto de construcción de cooperativas de trabajo

Edison Gastaldo - Um Tempo para Jogar: o 'ser brasileiro' na publicidade da Copa do Mundo de 1998

Entrevista

Roque de Barros Laraia - Entre a Antropologia e o Indigenismo: reflexões sobre uma trajetória

Tradução

Valerio Valeri - As Ilhas Salomão Descobertas pelos Europeus: do contrato social ao utilitarismo

Textos Informativos

Edilene Coffaci de Lima - Erros Repetidos: a pavimentação da BR-364 e os Katukina

Kimiye Tommasino - Notícia sobre os Guarani que Reivindicam a Terra de Araça'í

\section{Volume 02 - 2002}

Klaas Woortmann - A Idéia de Família em Malinowski

Ana Luiza Carvalho da Rocha e Cornelia Eckert - A Cidade, o Tempo e a Experiência de um Museu Virtual: pesquisa antropocronotopológica nas novas tecnologias

Aleksandar Boskovic - The "Intersubjective Turn" and the Question of Subject in Contemporary Anthropology: a review article

Denise Fagundes Jardim - Identidade Étnica e Recriação das Tradições entre os Migrantes de Origem Palestina no Extremo Sul do Brasil Antonádia Monteiro Borges - Cadê o Asfalto? Atos de governo e crônica política

Igor José de Renó Machado - Lugar Ampliado, Espaço e Poder

Stélio Marras - Ratos e Homens e o Efeito Placebo: um reencontro da cultura no caminho da natureza

Tradução

François Laplantine - Prefácio ao Livro de Roger Bastide Le Prochain et le Lontain

In Memorian

Maria Izabel Malinowski - Miguel Chase-Sardi (1924-2001)

\section{Volume 03 - 2003}

Edição especial - IV Reunião de Antropologia do Mercosul

Conferência

Mauro Barbosa de Almeida - Relativismo antropológico e objetividade etnográfica

Artigos

Gláucia de Oliveira Assis - “De Criciúma para o Mundo”: gênero, família e migração

Ciméa Bevilaqua - Etnografia do Estado: algumas questões metodológicas e éticas

Jurema Brites - Serviço Doméstico: elementos políticos de um campo desprovido de ilusões

Mariana Chaves - Vivir Juntos... Pero Separados. ¿Hacia una socialización en espacios homogéneos? 
Rachel Aisengart Menezes - Um Modelo para Morrer: última etapa na construção social contemporânea da pessoa?

Márcio Pizarro Noronha - Corpos do Futuro e o Futuro do Corpo. Metáforas corporais no cinema de horror e de ficção-científica e seus usos para a intervenção/invenção de direitos civis no âmbito da diferença/deficiência física

Mónica B. Rotman - Modalidades Productivas Artesanales: expresiones de 'lo local' en un mundo globalizado?

Fernando de Tacca - O Profano Sacralizado

Liliana Tamagno - Identidades, Saberes, Memoria Histórica y Prácticas Comunitarias. Indígenas tobas migrantes en la ciudad de La Plata, capital de la provincia de Buenos Aires, Argentina

Isabel Travancas - Em defesa do livro - intelectuais e imprensa nos anos 90

\section{Volume 04 - 2003}

Oscar Calávia Saez, Miguel Carid Naveira e Laura Perez Gil - O Saber é Estranho e Amargo. Sociologia e mitologia do conhecimento entre os Yaminawa

Renato Stutzman - Comunicações alteradas: festa e xamanismo na Guiana

Marcelo Mac Cord. - Identidades Étnicas, Irmandade do Rosário e Rei do Congo: sociabilidades cotidianas recifenses (século XIX)

João Valentin Wawzyniak - "Quem não quer de novo não cuida": processos de herança entre seringueiros de Rondônia

Leila Jeolás - Os Jovens e o Imaginário da Aids: notas para uma construção social do risco

Ana Luiza Carvalho da Rocha - Tecnologias Audiovisuais na Construção de Narrativas Etnográficas, um percurso de investigação

Ana Maria Spadafora - La Circularidad de la Experiencia de Campo: poder y desigualdad en la producción del conocimiento

Andréa Borghi M. Jacinto - Decifrando a Mãe do Jarro: uma construção do encontro etnográfico

Janine Helfst Leicht Collaço - Um Olhar Antropológico sobre o Hábito de Comer Fora

Textos Informativos

Ricardo Cid Fernandes - Notícia sobre os processos de retomada de Terras Indígenas Kaingang em Santa Catarina

Maria Dorothea Post Darella - A presença guarani no litoral de Santa Catarina: breve informe

\section{Volume 5 - 2004}

$N^{\circ} 05 / 1$

David Graeber - Catastrophe: Magic and History in Rural Madagascar

Lorenzo Macagno - Os Livros de Momade: Islã e 'saber local' no norte de Moçambique

Maria Catarina Chitolina Zanini - A Família como Patrimônio: a construção de memórias entre descendentes de imigrantes italianos

Mauro Guilherme Pinheiro Koury - Sistema de Nominação, Pertença, Medos e Controle Social: o uso dos apelidos entre um grupo de jovens da cidade de João Pessoa, Paraíba

Rogéria Campos de A. Dutra - Nação, Região, Cidadania: A construção das cozinhas regionais no Projeto Nacional Brasileiro Renata Menasche - Risco à Mesa: alimentos transgênicos, no meu prato não?

André Mendes Capraro - O Estádio Joaquim Américo - a "Arena da Baixada" - e a Identidade Clubística do Torcedor do Clube Atlético Paranaense

Luís Fernando Hering Coelho - Música Indígena no Mercado: sobre demandas, mensagens e ruídos no (des)encontro musical

Entrevista

Bartolomeu Melià - Jesuíta, Lingüista e Antropólogo: os Guarani como compromisso de vida

In Memorian

Simone Meucci - Octavio lanni (1926-2004)

\section{Volume 5 - 2004}

$n^{\circ} 5 / 2$

Silvia Montenegro - Antropologías Post-Coloniales: la antropología islámica y la islamización del conocimiento en ciencias sociales

Jair de Souza Ramos - Enredando Famílias: Estado e Família no Povoamento do Solo Nacional 
Alessandra Siqueira Barreto - Um Olhar sobre a Baixada: usos e representações sobre o poder local e seus atores

Luciana Hartmann - 'Revelando' Histórias: os usos do audiovisual na pesquisa com narradores da fronteira entre Argentina, Brasil e Uruguai

Eliska Altmann - Memórias de um Cabra Marcado pelo Cinema: representações de um Brasil rural

Laura Zapata - Una Antropología de la Gratuidad: prácticas caritativas y políticas de asistencia social en la Argentina

Naara Luna - Novas Tecnologias Reprodutivas: natureza e cultura em redefinição

Andréa Osório - Bruxas Modernas: um estudo sobre identidade feminina entre praticantes de wicca

Entrevista

Alcida Rita Ramos - Etnologia e Política Indígena em Movimento

Texto Informativo

Ciméa Barbato Bevilaqua - O Primeiro Vestibular Indígena na UFPR 
1. A Revista CAMPOS aceita as seguintes contribuições, que podem ser enviadas em português, inglês, francês ou espanhol (para publicação na língua original):

1.1 Artigos inéditos

Limite de aproximadamente trinta laudas, incluindo referências bibliográficas e notas.

\subsection{Ensaios bibliográficos}

Resenhas de um ou de vários livros, desde que tratem de temas correlatos.

Limite de aproximadamente vinte laudas, incluindo referências bibliográficas e notas.

\subsection{Resenhas bibliográficas}

Pequenas resenhas de livros recentes.

1.4 Outras contribuições

Pequenos textos de natureza acadêmica, informativa etc.

2. A pertinência para publicação será avaliada pela Comissão Editorial, no que diz respeito à adequação ao perfil e linha editorial da Revista, e por pareceristas ad hoc, no que diz respeito ao conteúdo e qualidade das contribuições.

3. Enviar pelo correio três cópias do texto, sem identificação do autor, em papel tamanho A4 (espaço 1,5 linha e margens laterais de três centímetros, fonte Times New Roman, corpo 12), e uma cópia em disquete (processador de texto compatível com a plataforma Windows). Os textos também podem ser enviados para o endereço eletrônico campos@ufpr.br.

4. Em folha à parte, incluir o título do artigo, nome do autor e dados profissionais (instituição, titulação, principais publicações), bem como endereço para correspondência (inclusive e-mail).

5. Os artigos devem estar acompanhados por resumo contendo entre 100 e 150 palavras, e por uma lista de até cinco palavras-chave, em português e inglês.

6. Colocar as notas ao final do trabalho. Incluir as referências bibliográficas no corpo do texto com o seguinte formato: sobrenome do autor/espaço/ano de publicação/dois pontos/espaço/página, conforme exemplo: Sahlins 1995: 43-47.

7. Para as referências bibliográficas, dispostas em ordem alfabética no final do trabalho, respeitar o formato que aparece nos seguintes exemplos:

a) livro

DUMONT, Louis. 1966. Homo hierarchicus: le système des castes et ses implications. Paris: Gallimard. 
b) coletânea

BOHANNAN, Paul (org.). 1967. Law and Warfare: studies in the anthropology of conflict. New York: The Natural History Press.

c) artigo de coletânea

GLUCKMAN, Max. 1940. "The Kingdom of the Zulu of South Africa". In M. Fortes \& E.P. Evans-Pritchard (orgs.) African Political Systems. London: Oxford University Press.

d) artigo em periódico

GEERTZ, Clifford. 1984. "Anti-anti Relativism". American Anthropologist 86(2): 263-77.

e) tese acadêmica

TURNER, Terence. 1966. Social Structure and Political Organization among the Northern Kayapó. Ph.D. Dissertation. Cambridge, MA: Harvard University.

8. Gráficos, quadros e mapas devem ser encaminhados em folhas separadas, numerados e titulados corretamente, com a devida referência (se reproduzidos de outra fonte) e com indicação do local de sua inserção no texto. Envia também o arquivo correspondente (em disquete ou por correio eletrônico), de maneira a permitir reprodução direta.

9. Com a publicação do artigo ou ensaio bibliográfico, o autor receberá cinco exemplares da Revista. No caso de resenhas, o autor receberá três exemplares da Revista.

10. Os ensaios bibliográficos e resenhas devem apresentar referência completa das obras analisadas, indicando o número de páginas de cada uma. As resenhas não devem receber título nem conter notas ou referências bibliográficas fora do texto.

11. A aceitação do trabalho implica a cessão de direitos autorais para publicação. A Revista não se compromete a devolver as colaborações recebidas.

12. Enviar os textos para:

\section{Revista Campos}

\section{Programa de Pós-Graduação em Antropologia Social - UFPR}

Rua General Carneiro, $460-6^{\circ}$ andar

80.060-150 Curitiba - Paraná - Brasil

Tel.: (41) 3360-5272

E-mail: campos@ufpr.br 


\section{Sistema Eletrônico de Revistas da UFPR www.prppg.ufpr.br}

A Universidade Federal do Paraná instituiu o Sistema Eletrônico de Revistas (SER), por meio do qual abre um importante canal de interação entre usuários e comunidade científica em geral. Neste espaço estão listadas as revistas técnico-científicas publicadas com recursos próprios ou com recursos do Programa de Apoio à Publicação da UFPR.

O SER utiliza-se do Open Journal System, que é um software livre e com protocolo internacional, permitindo a submissão de artigos e o acesso às revistas de qualquer parte do mundo. Nesse sistema estão cadastradas 25 revistas da UFPR, abrangendo diversas áreas de conhecimento. O Departamento de Informática da UFPR está encarregado da implantação e gerenciamento do sistema.

O Sistema pode ser acessado por autores, para a submissão de trabalhos, consultores, para a avaliação dos trabalhos, editores, para o gerenciamento do processo editorial e usuários interessados em acessar e/ou obter cópias de artigos já publicados.

A submissão de artigos pode ser feita por meio eletrônico e o autor poderá fazer o acompanhamento passo a passo do processo de avaliação por parte dos consultores, até a editoração final. As normas de publicação e demais instruções aos autores, bem como os endereços dos editores, são encontrados nas páginas de cada revista. 

